\title{
Influence of Nano Silica on the Geotechnical Properties of Clayey Soil Stabilized with Lime
}

\author{
R. Iswarya ${ }^{1}$ and V. Satheeskumar ${ }^{2}$ \\ ${ }^{1}$ PG Student, ${ }^{2}$ Assistant Professor, \\ Department of Civil Engineering, Government College of Technology, Coimbatore, Tamil Nadu, India \\ E-Mail: riswaryasalem@gmail.com, satheeskumar@gct.ac.in
}

\begin{abstract}
The soil must be able to withstand the load and transfer it to ground within the range of allowable deformations, for which it must possess good physical and geotechnical properties. The conventional method of stabilization such as removal and replacement of ill - suited soils incur higher cost and is time consuming. A new method of stabilization, designated as chemical stabilization can be adopted. This method initiate chemical reactions such as cation exchange, pozzolanic activity etc., which consequently enhance the geotechnical properties of soil. In this study, the mechanical behavior of soil is improved by addition of nanoparticles i.e., nano silica along with cementitious material, lime. Considering economic issues of nano silica usage and results of this research in soil stabilization projects, in this study $0,1,3$ and $5 \%$ weight of nano silica is used as well as 0 , 2 and $4 \%$ weight of lime is used. The effect of these replacements is studied by Atterberg limits test, compaction test and unconfined compressive strength (UCS) test. The effect of curing time on samples at 3, 7 and 28 days of age has also been investigated. The optimum percentage replacement of nano silica in lime stabilized soil is determined. The microstructure of the stabilized soil is studied by Scanning electron microscopy (SEM) test. Thus the results proved that there is a significant improvement in the plasticity, compaction and strength properties with slight addition of nano silica in clayey soil mixed with lime.
\end{abstract}

Keywords: Compaction, Lime, Nano Silica, Plasticity, Stabilization, Unconfined Compressive Strength

\section{INTRODUCTION}

The present day needs demands the construction on soils having poor geotechnical properties. Clayeysoil is one such ill - suited soil which in lightly loaded foundation systems, cause irreversible failures to structures due to the applied stresses. The physical and geotechnical properties of soils can be widely improved by the process of soil stabilization. The usual method of stabilization which includes replacing the problematic soil by strong materials such as gravely soil, geogrids, geotextiles and concrete incur higher cost and is time consuming. To overcome these difficulties one of the techniques that has been used effectively with success in practice is chemical stabilization.In chemical stabilization the ill - suited soil is blended with the stabilizers in order to initiate a suite of chemical reactions such as cation exchange, flocculation, carbonation and pozzolanic activity which consequently enhance the geotechnical properties of the soil.
Nanotechnology can be applied in geotechnical engineering in order to improve the properties of the ill - suited soil as the chemical reactions in soils and rocks usually occur in nano scale due to the nano size of their minerals. An activator substance such a lime is needed in order to influence the reactivity of nano silica [6]. In this study, the effect of adding nano silica as a pozzolanic additive on the geotechnical properties of clayey soil stabilized with lime is analyzed. A high pozzolanic activity of nano silica compared to micro silica is indicated through research on pozzolanic activity of silica nanoparticles [6]. Structure of cementitious material becomes denser and more uniform, even in a short time of curing as the silica nanoparticles acts as an accelerator [12].

When nano silica is added to wet soil, lime decomposes to $\mathrm{Ca}^{++}$and $2(\mathrm{OH})^{-}$ions and soil $\mathrm{pH}$ level increases. In such case, the dissolved silicate and $\mathrm{Si}$ ions in nano silica are combined with $(\mathrm{OH})^{-}$ions which produces $\mathrm{Si}(\mathrm{OH})_{3}$ which in turn combine with $\mathrm{Ca}^{++}$ions to shape cementitious gels called hydrated calcium silicate (CSH). These cementitious gels penetrate through voids and poresin the soil texture which in turn results in increased soil strength $[15,2]$.

$$
\begin{aligned}
& \mathrm{Ca}(\mathrm{OH})_{2} \rightarrow \mathrm{Ca}^{2+}+2(\mathrm{OH})^{-} \\
& \mathrm{Ca}^{2+}+2(\mathrm{OH})^{-}+\mathrm{SiO}_{2} \rightarrow \mathrm{CaO} \cdot \mathrm{SiO}_{2}+\mathrm{H}_{2} \mathrm{O}(\mathrm{CSH})(2)
\end{aligned}
$$

\section{OBJECTIVES OF THE STUDY}

1. To study the geotechnical properties of the treated soils in order to optimize the amount of additives to be used in the stabilization process.

2. To analyze the chemical reactions that is responsible for the enhancement in the geotechnical properties of the soil.

3. To analyze the texture of the stabilized soil.

\section{MATERIALS AND METHODS}

\section{A. Materials}

The materials used in this study and their properties are listed below

\section{Soil Sample}

Soil sample as shown in Fig .1 is collected in Government College of Technology, Coimbatore. The locations latitude 
and longitude are $11.02 \mathrm{~N}$ and $76.93 \mathrm{E}$ respectively. The soil sample for this study is collected at a depth of $1.5 \mathrm{~m}$ below ground level. Laboratory tests as per IS 2720 standard were conducted in order to evaluate the index and engineering properties of the collected soil sample and the values are presented in Table I.

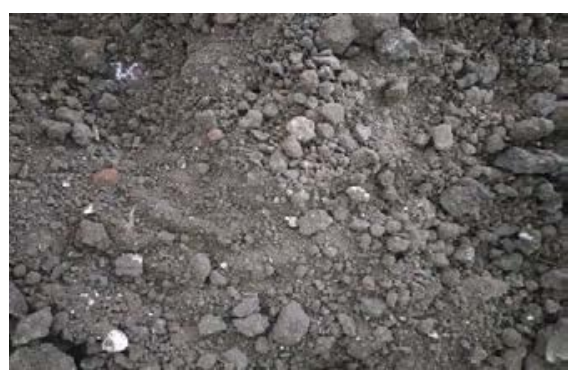

Fig. 1 Soil Sample

TABLE I PROPERTIES OF SOIL

\begin{tabular}{|c|l|c|}
\hline S. No & \multicolumn{1}{|c|}{ Properties } & Values \\
\hline 1 & Natural Moisture Content (\%) & 6 \\
\hline 2 & Specific Gravity & 2.67 \\
\hline 3 & Percentage of Gravel (\%) & 0.1 \\
\hline 4 & Percentage of Sand (\%) & 20.8 \\
\hline 5 & Percentage of Silt (\%) & 9.35 \\
\hline 6 & Percentage of Clay (\%) & 69.55 \\
\hline 7 & Liquid Limit $\left(\mathrm{W}_{\mathrm{L}}\right)$ & 68 \\
\hline 8 & Plastic Limit ( $\left.\mathrm{W}_{\mathrm{P}}\right)$ & 30 \\
\hline 9 & Plasticity Index ( $\left.\mathrm{I}_{\mathrm{P}}\right)$ & 38 \\
\hline 10 & Optimum Moisture Content (\%) & 18.2 \\
\hline 11 & Maximum Dry Density (g/cc) & 1.78 \\
\hline 12 & $\begin{array}{l}\text { Unconfined Compressive Strength } \\
\left(\mathrm{kN} / \mathrm{m}^{2}\right)\end{array}$ & 196 \\
\hline 13 & Soil type & $\mathrm{CH}$ \\
\hline
\end{tabular}

\section{Nano Silica}

The amorphous silica nano particles used in this project as shown in Fig. 2 is purchased from Astra Chemicals Pvt. Ltd., Chennai.Its physical and chemical composition is obtained from the manufacture and is presented in Table II.

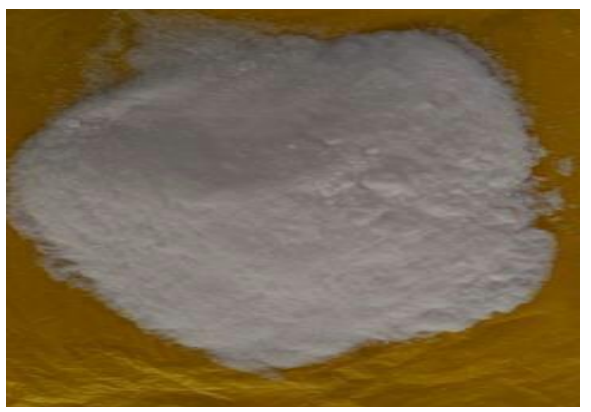

Fig. 2 Nano Silica
TABLE II PROPERTIES OF NANO SILICA

\begin{tabular}{|c|l|c|}
\hline S. No & \multicolumn{1}{|c|}{ Properties } & Values \\
\hline 1 & Specific Surface Area $\left(\mathrm{m}^{2} / \mathrm{g}\right)$ & 202 \\
\hline 2 & $\mathrm{pH}$ Value & 4.12 \\
\hline 3 & $\mathrm{SiO}_{2}$ Content (\%) & 99.8 \\
\hline 4 & Carbon Content (\%) & 0.06 \\
\hline 5 & $\mathrm{Chloride} \mathrm{Content} \mathrm{( \% )}_{2}$ & 0.009 \\
\hline 6 & $\mathrm{Al}_{2} \mathrm{O}_{3}(\%)$ & 0.005 \\
\hline 7 & $\mathrm{TiO}_{2}(\%)$ & 0.004 \\
\hline 8 & $\mathrm{Fe}_{2} \mathrm{O}_{3}(\%)$ & 0.001 \\
\hline 9 & $\mathrm{Purity}^{(\%)}$ & 99.88 \\
\hline 10 & Size of the particles (nm) & $5-10$ \\
\hline 11 & Specific Gravity & $1.29-1.31$ \\
\hline
\end{tabular}

\section{Lime}

Lime with specific weight of $540 \mathrm{~kg} / \mathrm{m}^{3}$ as specified by the manufacturer is used as a cementitious material in this project.

\section{B. Experimental Method}

In this study nano silica is added to the clayey soil stabilized with lime and its effects are investigated. Here 0, 1, 3 and $5 \%$ weight of nano silica as well as 0,2 and $4 \%$ weight of lime is used. The percentage addition of nano silica and additive are chosen from the previous studies on stabilization using nanomaterial's [6] The effect of curing times on samples at 3, 7 and 28 days of age has also been investigated.

\section{Sample Making Method}

Three mixes of samples were made and the tests were conducted. The first mix includes the soil samples without additives, the second mix contains soil with 2 and $4 \%$ of lime and the third mix is the soil with lime and 1, 3 and 5\% of nano silica. First, different percentages of nano silica and lime is added to the soil in a container and mixed. After mixing for around 30 minutes, distilled water is added in stages and mixed in order to produce a homogenous mixture. In order to analyse the effect of stabilizer on the soil consistency limits, Atterberg limits tests are conducted on samples after 48 hours of addition of the stabilizer and additive[9] The 3, 7 and 28 days compressive strength tests are conducted on samples that had been kept under curing after extraction. Three samples for each mix proportions were tested and its average value is noted and the results are analyzed.

\section{RESULTS AND DISCUSSION}

The results of the experimental study carried out on the lime stabilized clayey soil with nano silica are discussed below. 


\section{A. Atterberg Limits Tests}

Consistency tests are performed as per IS 2720 Part-V

standard. The variation in the plasticity characteristics of clayey soil with varying proportions of lime and nano silica are shown in Fig. 3.
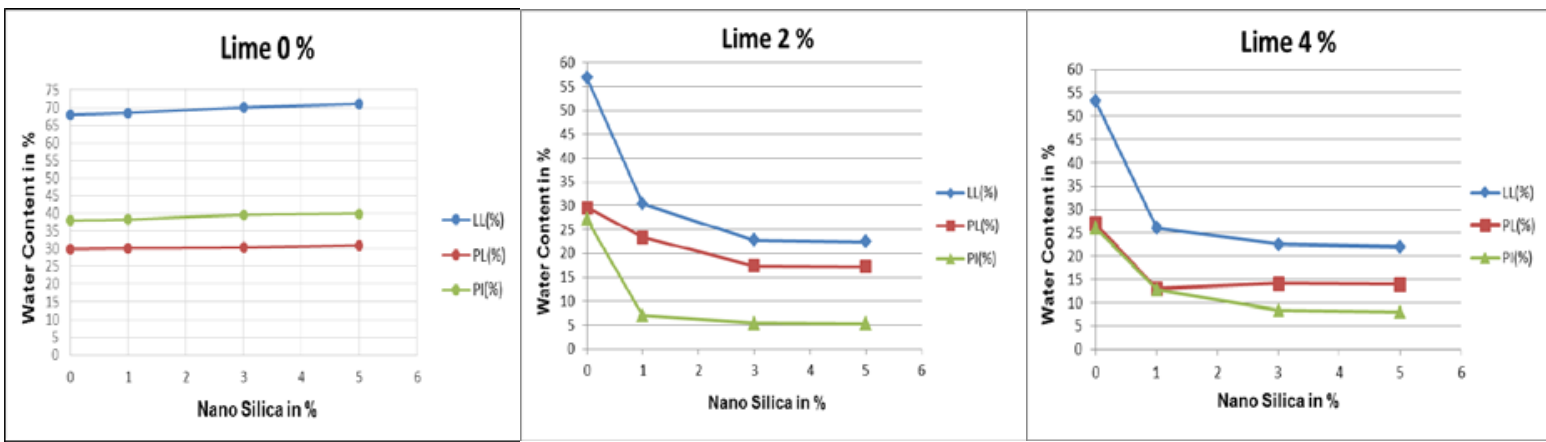

Fig. 3 Changes in Atterberg Limits Values with Different Percentage of Lime and Nano Silica

Experimental results reveal that when clayey soil is mixed with nano silica without lime, the plasticity characteristics increase slightly with increase in percentage addition of nano silica. This slight increase may be accounted due to high specific surface of nano silica due to its very small size [6]. When a cementitious material, lime is added with nano silica, the plasticity characteristics of the clay are found to decrease with increase in percentage addition of nano silica. This decrease in the plasticity characteristics is due to cation exchange reaction between $\mathrm{CaO}$ in limestone and $\mathrm{SiO}_{2}$ in nano silica, as a result of which clay particles come closer to form a coarse grained texture leading to improvement in plasticity properties of the clayey soil.It can also be noted that, there occurs a significant change in the plasticity characteristics only up to $3 \%$ addition of nano silica. Between $3-5 \%$ addition there occurs no considerable change. So with reference to the consistency limits, 3\% replacement of nano silica is preferable.

\section{B. Compaction Test Results}

Standard Proctor Compaction tests areperformedas per IS 2720 Part-VII standard.

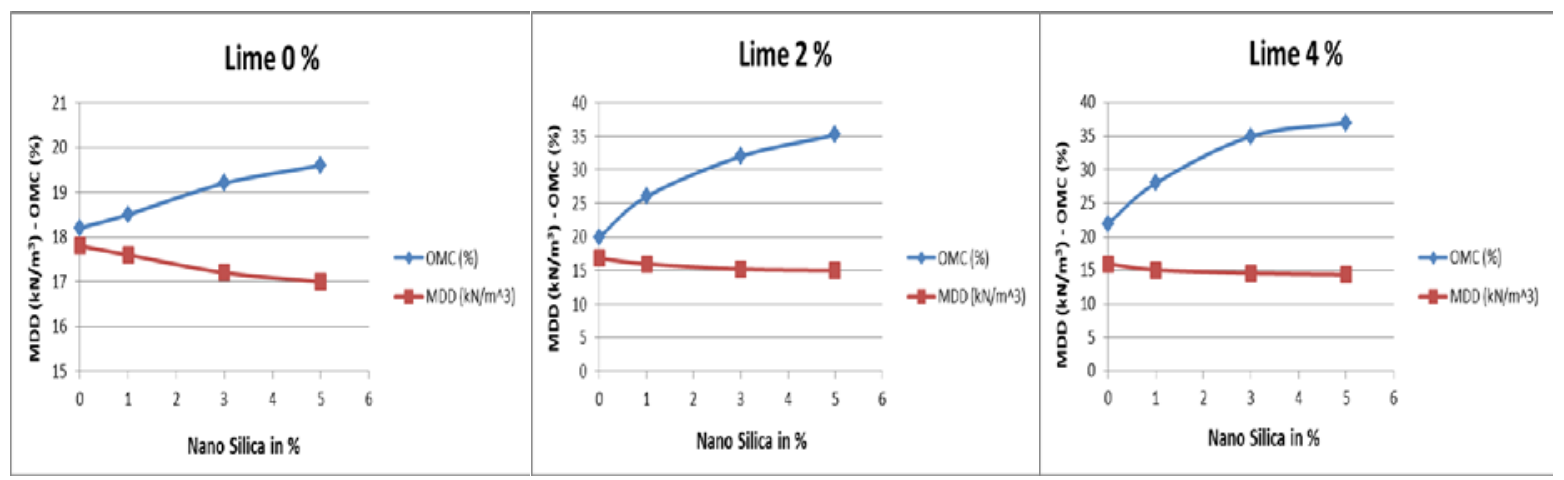

Fig. 4 Changes in Maximum Dry Density and Optimum Moisture Content Values with Different Percentage of Lime and Nano Silica

From the Fig. 4 it can be inferred that the optimum moisture content increases with increase in percentage addition of nano silica in all the three cases and maximum dry density value decreases with increase in percentage addition of nano silica. This increase may be due to high specific surface of nano silica due to its small size. Moreover, the soil particles are flocculated due to rapid reactivity properties of silica nanoparticles with lime causing soil particles to need more water to move on each other [6].It can also be seen that considerably variations in dry density can be noted only up to addition of $3 \%$ of nano silica. Between $3-5 \%$ addition there occurs no considerable change. So, small replacement percentage can make the soil more workable.

\section{Compressive Strength Test Results}

Unconfined compressive strength tests are performed as per IS 2720 Part- X standard. Fig. 5 shows the variations in the compressive strength characteristics of clayey soil with varying proportions of lime and nano silica on 3, 7 and 28 days test. 

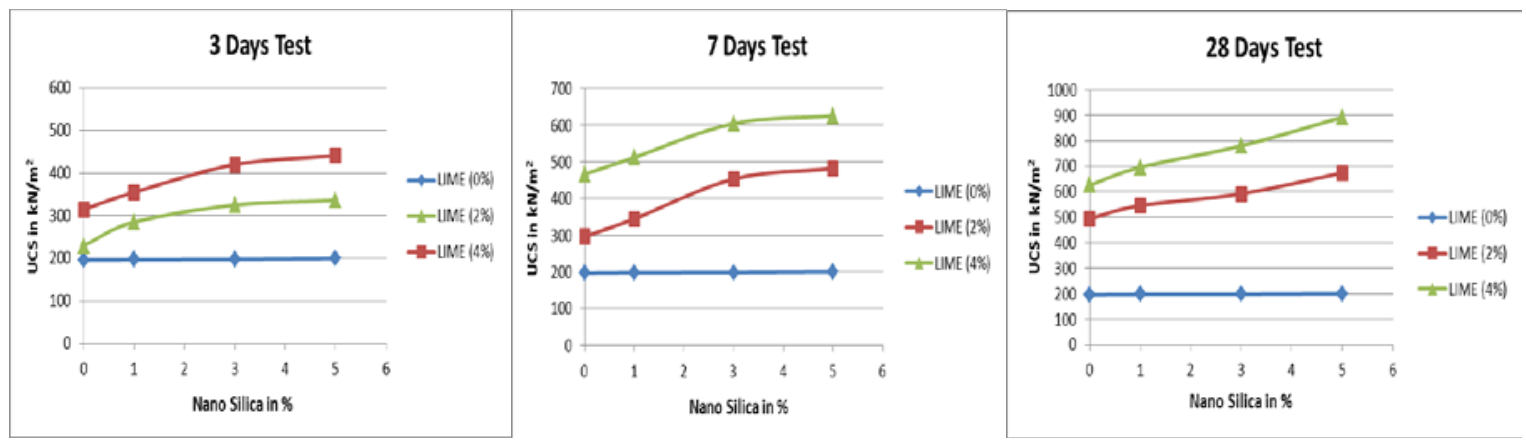

Fig. 5 Changes in Compressive Strength Values with Different Percentage of Lime and Nano Silica on 3, 7 And 28 Days Test

From Fig. 5 it can be inferred that there occurs no significant changes in the compressive strength of the clayey soil with increase in addition of nano silica without lime, at every curing conditions. A slight increase in the strength occurs due to filling of the voids as a result of mechanical compaction [1]3 and the 7 days compressive strength tests reveal that the compressive strength increases with increase in percentage addition of nano silica up to $3 \%$ for both $2 \%$ and $4 \%$ replacement of lime as a result of formation of cementitious material due to reaction of lime with nano silica. Between $3-5 \%$ addition of nano silica there is only slight increase in strength, this may be due to increased moisture of samples with increase in addition of nano silica [6].
Unlike the 3 and 7 days test, the 28 days test results reveal that the compressive strength increases with increase in addition of nano silica even after 3\% addition, for both $2 \%$ and $4 \%$ replacement of lime. This signifies the effect of curing time on samples, as the strength of 28 days sample continues to increase with $5 \%$ addition of nano silica.Moreover the compressive strength of the samples with $4 \%$ lime is found to be higher compared to that with $2 \%$ lime due to increase in the additive content resulting in increase in formation of cementitious material.

\section{SEM Analysis}

The images shown in Fig. 6 is the result of the SEM analysis done on the stabilized clay sample.

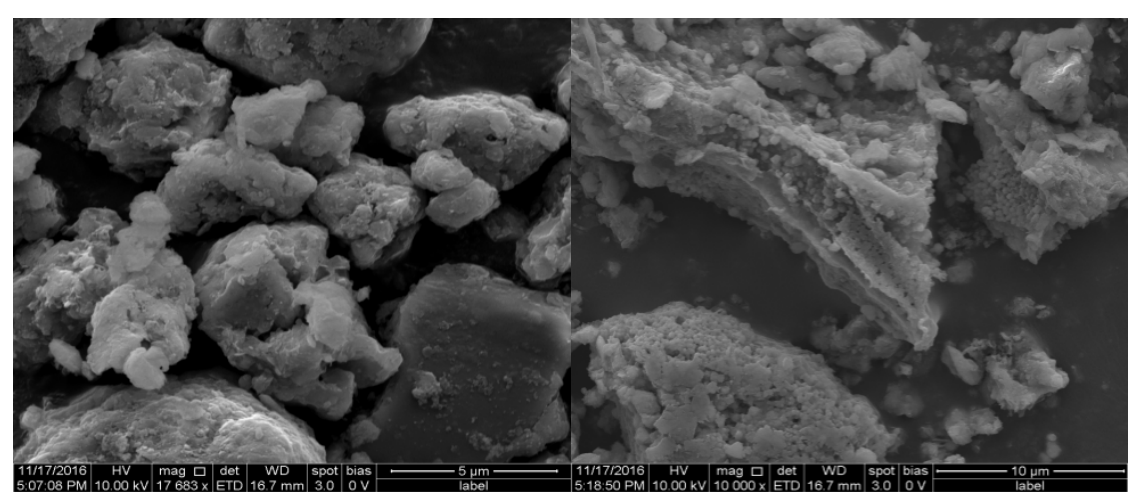

Fig. 6 SEM Images (Stabilized Soil)

The SEM images shows the formation of cementitious material i.e., hydrated calcium silicates which fills the voids in soil and results in increased soil strength.

\section{CONCLUSIONS}

The following conclusions are drawn based on the experimental investigations carried out in the clay sample.

1. Addition of nano silica alone does not create any greater impact in improving the engineering properties of the soil.

2. The improvement in the plasticity, compaction and strength properties are encountered due to high reactivity of nano silica with the additive, lime.
3. With reference to the experimental results obtained from the consistency limits test, 3\% addition of nano silica and $2 \%$ addition of lime are considered to be the optimum.

4. Eliminating the effects of curing, considering $3 \%$ addition of nano silica to be optimum with reference to the strength characteristics, $31.75 \%$ increase in strength is obtained with $4 \%$ addition of lime compared with $2 \%$ lime addition at 28 days.

5. The effect of curing comes into play with increase in strength at 28 days even after $3 \%$ addition of nano silica. On 7 days test, with increase in addition of nano silica from $3-5 \%$, the increase in strength is only 
$4 \%$,but on 28 days test, the increase is found to be around $14 \%$.

6. From the experimental analysis, $3 \%$ addition of nano silica and $2 \%$ addition of lime is considered to be optimum. With this replacement percentage, the strength of the stabilized sample is increased by around 202\% compared with the unstabilized one.

7. $4 \%$ addition of lime can be preferred for works that necessitates greater strength improvement.

8. From the SEM analysis, the texture of the stabilized sample and the presence of surface reaction are identified.

Particle agglomeration is a problem that's been encountered while using nano silica as a stabilizer. As a future scope, dispersion studies can be done in order to overcome such a problem.

\section{REFERENCES}

[1] Antonio Alberto S. Correia and Maria Graca Rasteiro, "Nanotechnology Applied to Chemical Soil Stabilization", International Conference on Transportation Geotechnics, Vol. 143, pp. 1252-1259, June 2016.

[2] F. G. Bell, "Lime Stabilization of Clay Minerals and Soil”, Journal of Engineering Geology, Vol. 42, pp. 223-237, 1996.
[3] Ebrahim Nohani and Ezatolah Alimakan, "The Effect of Nano Particles on Geotechnical Properties of Clay”, International Journal of Life Science, Vol. 9, pp. 25 -27, 2015.

[4] Foad Changizi and Abdo Ihosein Haddad, "Strength Properties of Soft Clay Treated with Mixture of Nano-SiO 2 and Recycled Polyester Fiber”, Journal of Rock Mechanics and Geotechnical Engineering, Vol. 7, pp. 367 - 378, 2015.

[5] P. Hareesh and R. Vinothkumar, “Assessment of Nano Materials on Geotechnical Properties of Clayey Soils”, International Conference on Engineering Innovations and Solutions, pp. 66 - 70, 2016.

[6] Mohammad Ali Pashabavandpouri and Sajad Jahangiri, "Effect of Nano-Silica on Swelling, Compaction and Strength Properties of Clayey Soil Stabilized with Lime”, Journal of Applied Environmental and Biological Sciences, Vol. 5, No. 7S, pp. 538-548, May 2015.

[7] Muzahim Al-Mukhtar, Abdelmadjid Lasledj and J.F. Alcover, "Lime Consumption of Different Clayey Soils”, Applied Clay Science,Vol. 24, pp. 1-13, 2014.

[8] Navid ghasabkolaei, Asskar janalizadeh choobbasti, Nader roshan and Seiyed E. Ghasemi, "Geotechnical Properties of the Soils Modified with Nano Materials: a Comprehensive Review”, Archives of Civil and Mechanical Engineering,Vol. 17, pp. 639-650, 2017.

[9] L.K. Sharma, N.N. Sirdesai, K. M. Sharma and T.N. Singh,”Experimental study to examine the independent roles of lime and cement on the stabilization of a mountain soil: A comparative study”, Applied Clay Science., Vol. 10, pp. 1-13, Nov. 2017.

[10] Sanusha Babu and Shyla Joseph, "Effect of Nano Materials on Properties of Soft Soil”, International Journal of Science and Research, Vol. 5, No. 8, pp. 634 - 637, 2016.

[11] Sayed Hessam Bahmani, Bujang B. K. Huat, Afshin Asadi and Nima Farazadnia, "Stabilization of Residual Soil Using $\mathrm{SiO}_{2}$. 